JHR

36,5

908

Received 10 February 2021 Revised 30 March 2021 Accepted 11 May 2021

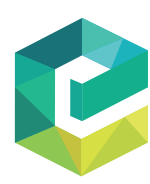

Journal of Health Research Vol. 36 No. 5,2022 pp. $908-918$

Emerald Publishing Limited e-ISSN: 2586-940X

p-ISSN: 0857-4421

DOI 10.1108/JHR-02-2021-0099

\section{The impact of resiliency on mental health and quality of life among older adults in Thailand}

\author{
Paul Ratanasiripong \\ College of Education, California State University, Long Beach, California, USA \\ Nop Ratanasiripong \\ School of Nursing, California State University - Dominguez Hills, Carson, \\ California, USA \\ Monpanee Khamwong \\ Boromarajonani College of Nursing, Bangkok, Thailand \\ Sarinya Jingmark \\ Udon Thani Rajabhat University, Udon Thani, Thailand \\ Ploenpit Thaniwattananon \\ Prince of Songkla University, Songkhla, Thailand \\ Pennapa Pisaipan \\ Phrapokklao Nursing College, Chanthaburi, Thailand \\ Ladda Sanseeha \\ Mahasarakham University, Maha Sarakham, Thailand \\ Nongnaphat Rungnoei \\ Prachomklao College of Nursing, Petchaburi, Thailand \\ Wallapa Songprakun \\ Payap University, Chiang Mai, Thailand \\ Asawinee Tonkuriman \\ Mae Fah Luang University, Chiang Rai, Thailand, and \\ Suchart Bunyapakorn \\ Nongkham Hospital, Nakhonratchasima, Thailand
}

\begin{abstract}
Purpose - The aim of this study was to examine the impact of resiliency and associated factors on the mental health and quality of life among older adults in Thailand.

Design/methodology/approach - This cross-sectional study was conducted with 1,800 older adults $(M=69.3$, SD $=7.2)$ from nine provinces across all regions of Thailand. Each participant completed an anonymous paper-based survey that included demographic data, work activities, health behaviors, social
\end{abstract}

\footnotetext{
(C) Paul Ratanasiripong, Nop Ratanasiripong, Monpanee Khamwong, Sarinya Jingmark, Ploenpit Thaniwattananon, Pennapa Pisaipan, Ladda Sanseeha, Nongnaphat Rungnoei, Wallapa Songprakun, Asawinee Tonkuriman and Suchart Bunyapakorn. Published in Journal of Health Research. Published by Emerald Publishing Limited. This article is published under the Creative Commons Attribution (CC BY 4.0) licence. Anyone may reproduce, distribute, translate and create derivative works of this article (for both commercial and non-commercial purposes), subject to full attribution to the original publication and authors. The full terms of this licence may be seen at http://creativecommons.org/licences/by/4.0/ legalcode
} 
support, Connor-Davidson Resilience Scale (CD-RISC), Depression, Anxiety, Stress Scale (DASS) and World Health Organization Quality of Life Assessment for Older Adults (WHOQOL-OLD).

Findings - Through hierarchical multiple regression, resiliency, social support, exercise and work hours per week were found to be significant predictors of mental health: depression $(F(6,520)=19.38, p<0.001$, adjusted $\left.R^{2}=0.17\right)$; anxiety $\left(F(6,520)=18.64, p<0.001\right.$, adjusted $\left.R^{2}=0.17\right) ;$ stress $(F(6,521)=12.91, p<.001$, adjusted $\left.R^{2}=0.12\right)$. Five predictors of quality of life were identified through hierarchical multiple regression: resiliency, social support, exercise, age and family economic status. These predictors explained $35 \%$ of the variance, $F(5$, $1655)=178.44, p<0.001$, adjusted $R^{2}=0.35$.

Originality/value - Based on the results of this study, a comprehensive Wellness Program was designed to improve the mental health and quality of life of older adults in Thailand. This Wellness Program included five components: Volunteer Program, Resiliency Building Program, Social Support Program, Exercise Program, and Financial Education Program.

Keywords Resilience, Social support, Depression, Anxiety, Stress, Quality of life, Thailand

Paper type Research paper

\section{Introduction}

With global increase in life expectancy and reduction in fertility rate, the proportion of older adults in the world will grow from $9 \%$ in 2019 to $16 \%$ in 2050 [1]. In 2019, global older adult population was approximately 703 million and is expected to grow by $120 \%$ to 1.55 billion in 2050, with the largest increase in East and Southeast Asia [2]. There were over 260 million older adults that resided in East and Southeast Asia in 2019, the largest share (37\%) of global older adult population [2]. Southeast Asia has three of the top ten countries for projected percentage increase in older adult population between 2019 and 2050, with Singapore ranking second (20.9\% increase), Thailand ranking sixth (17.2\% increase) and Brunei Darussalam ranking tenth (16.5\% increase) [2]. As the older adult population in Thailand continue to grow, it is vital to identify factors that impact their mental health and quality of life.

While there have been several studies with older adult population and quality of life issues in Thailand, there are only limited research on their resiliency, mental health and social support $[3,4]$. Additionally, previous mental health studies have focused more on their depression with limited focus on anxiety and stress. There have been limited studies on resiliency and mental health among older adults in Thailand [5].

A few recent studies found high prevalence of depression among Thai older adults [6, 7]. Poor social support has also been associated with depression among Thai older adults; specifically, poor social support included living alone, not receiving support from family, difficulties in relationships with family members and lack of reciprocity with neighbors [4].

Resilience is described as the ability of the person to cope with or adapt to stressful life events or adversity [8]. Key features for older adult resilience have been found to include social, physical and mental factors [9]. One study on older adults in Thailand found resilience to have direct effect on well-being and life satisfaction [10]. Another study outside Thailand has found resilience to mediate the relationship between social support and quality of life [11].

The aim of this study is to (1) examine the impact of resiliency on the mental health and quality of life among older adults in Thailand; (2) explore additional factors associated with mental health and quality of life among older adults in Thailand, including social support, health behaviors, work activities and other demographic variables; (3) propose a comprehensive Wellness Program for older adults. The conceptual framework for this study is illustrated in Figure 1. The findings from this study will provide recommendations for intervention programs and services to improve the well-being of older adults in Thailand.

\section{Methods}

Study population and data collection

This cross-sectional study recruited volunteer participants from villages, community centers and elderly schools in nine provinces across all regions of Thailand (North, Northeast,
Older adult mental health and quality of life 
JHR

910

Figure 1.

Conceptual framework for mental health and quality of life

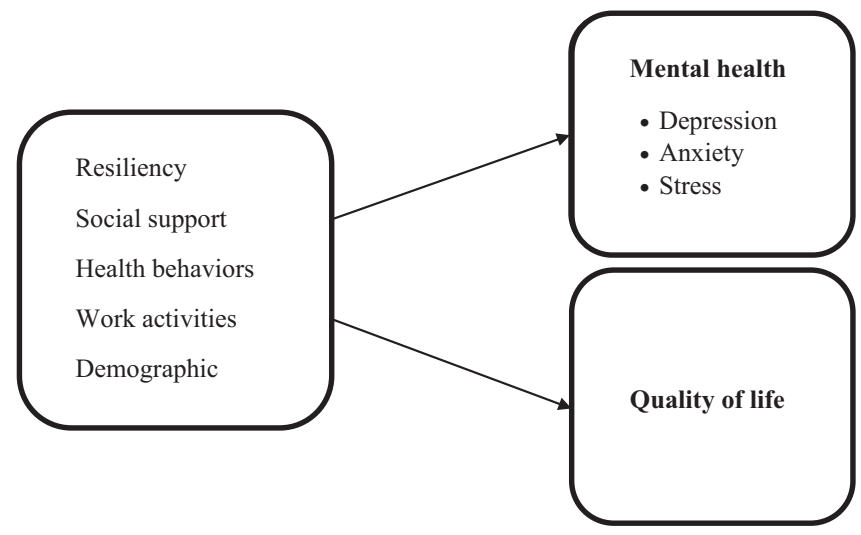

Central, East, South). Inclusion criteria included: age 60 and older, capable of written or verbal communication, and capable of voluntary consent to participate in the study. Exclusion criteria included: cognitive impairment and temporary migrant worker status.

At each data collection site, volunteer participants were selected if they meet the inclusion criteria and do not meet the exclusion criteria. Participants were asked to complete the anonymous paper-based survey that took approximately 25 min to complete. Participants may skip any questions or stop the survey at any time. Data collection staff read each survey question to participants who had difficulties reading the survey but could comprehend the questions. Data collection continued at each site until at least 200 participants have been reached. After completing the anonymous survey, each participant had an option to submit the name on a separate piece of paper to enter into a random drawing for a prize of 500 Thai Baht (US\$16).

\section{Instruments}

The Connor-Davidson Resilience Scale (CD-RISC) was used to measure the level of resiliency among older adults $[8,12]$. CD-RISC comprised 25 items that participants rated on a five-point Likert scale. The Thai version of CD-RISC measured self-efficacy, support resources, personal competence and tolerance of negative affect [12]. Higher score indicated higher level of resiliency. For this study, the Cronbach's alpha for CD-RISC was 0.95.

The Depression, Anxiety, Stress Scale (DASS) was used to assess mental health, specifically the levels of depression, anxiety and stress among older adults [13]. DASS comprised 21 items (seven items per subscale) that participants rated on a four-point Likert scale. Higher score indicated more symptoms. For this study, the Cronbach's alpha for DASS was 0.83 for depression, 0.86 for anxiety and 0.84 for stress.

The World Health Organization, Quality of Life Assessment of Older Adults (WHOQOLOLD) was used to measure the quality of life of older adults [14]. WHOQOL-OLD comprised 24 items that participants rated on a five-point Likert scale. Higher score indicated better quality of life. For this study, the Cronbach's alpha for WHOQOL-OLD total score was 0.87. Since the focus was on the overall quality of life of older adults, this study did not use the domain scores of this scale.

Social support was measured by two items that specify the level of support received from family and friends. Participants rated each item from 1 (very low) to 10 (very high). The Cronbach's alpha for social support was 0.71 .

Demographic data collected include age, gender, marital status and family economic status. Health behaviors include exercise frequency, drinking frequency and number of 
cigarettes smoked per day. Work activities included working status and number of work hours per week.

\section{Statistical analysis}

All statistical analyses were performed with IBM SPSS 24. Descriptive statistics (frequency, percentage, mean and SD) were used to describe participant characteristics, resiliency, mental health and quality of life. Normal distributions were checked via normal Q-Q Plot. Spearman's Rho or Pearson's Product Moment correlation coefficients were used to examine the relationships between variables of interest and demographic variables. Hierarchical multiple regressions were utilized to identify the predictors of the outcome variables.

\section{Ethical considerations}

The protocol for this study was approved by the university institutional review board (Reference \#20-112). All procedures performed involving human participants were in accordance with the ethical standards of the university IRB and with the 1964 Helsinki declaration and its later amendments or comparable ethical standards.

\section{Results}

\section{Participant characteristics}

A total of 1,807 qualified older adults from nine provinces in all regions of Thailand participated in the study. However, seven of them had more than $20 \%$ missing data. Thus, 1,800 participants were included in the data analyses with approximately 200 older adults from each province. The average age of the participants was 69.3 years old $(\mathrm{SD}=7.2$, range $=60-95)$. More than half $(63.3 \%)$ were female. Approximately $41 \%$ of the participants were not married ( $6.1 \%$ single, $0.3 \%$ divorced, $30.9 \%$ widowed). A third of them (34.2\%) still worked with the average working hours of 32.1 . About $85.1 \%$ noted their economic status between average and very good.

Approximately, a third of participants (32.1\%) exercised regularly, at least 3 times per week. The majority of participants were non-smokers $(91.7 \%)$ and non-drinkers $(86.9 \%)$. Among smokers, the average number of cigarettes per day was 7.8. Among drinkers, the frequency of drinking was 3.0 times per week. Participants reported receiving good social support from family and friends $(M=15.0, \mathrm{SD}=3.1)$. Their mean score for resiliency was $62.3(\mathrm{SD}=19.6)$. See Table 1 .

\section{Mental health and quality of life}

The measured mental health variables in this study included depression, anxiety and stress. The mean score of depression was $8.3(\mathrm{SD}=8.8$, range $=0-42)$, of anxiety was $8.3(\mathrm{SD}=8.3$, range $=0-42)$, of stress was $11.2(\mathrm{SD}=8.5$, range $=0-42)$. The mean score of older adults' quality of life was 71.8 ( $\mathrm{SD}=10.8$, range $=30-103$ ).

The outcome variables in this study were depression, anxiety, stress and quality of life. The results showed various significant relationships between the variable of interests and the outcome variables (Table 2). Exercise frequency, social support and resiliency were consistently associated with the depression, anxiety, stress and quality of life.

Higher level of depression was significantly related to not being married $(r=-0.09)$, less work hours per week $(r=-0.23)$, poorer family economic status $(r=-0.13)$, less frequent exercise $(r=-0.07)$, lower social support $(r=-0.27)$ and lower resiliency $(r=-0.15)$. Higher level of anxiety was significantly related to less work hours per week $(r=-0.23)$, not being
Older adult mental health and quality of life 
JHR

36,5

\begin{tabular}{lcr}
\hline Variables & Frequencies & $\%$ \\
\hline Gender $(n=1,796)$ & & \\
Females & 1137 & 63.3 \\
Males & 659 & 36.7 \\
Marital status $(n=1,797)$ & & \\
Not married (single, divorced, widowed) & 743 & 51.3 \\
Married & 1,054 & 58.7
\end{tabular}

Working status $(n=1,785)$

Did not work

1,174

58.7

Work

65.8

611

34.2

Family economic status $(n=1,796)$

Very poor

0.6

Poor

11

8.4

Average

151

1,366

76.1

Good

Very good

$\begin{array}{rr}253 & 0.9\end{array}$

Exercise frequency $(n=1,792)$

None

Less than 1 time/week

1-2 times/week

$\begin{array}{ll}456 & 25.4 \\ 513 & 286\end{array}$

Routinely (3 times or more/week)

Smoking status $(n=1,792)$

Smoker

Non-smoker

Drinking status $(n=1,796)$

148

.

Drinker

55.6

Non-drinker

44.4

Health status $(n=1,796)$

Had chronic condition(s)

38.3

No chronic condition

61.7

\begin{tabular}{lcr}
\hline Variables & Mean (SD) & Min-Max \\
\hline Age $(n=1791)$ & $69.3(7.2)$ & $60-95$ \\
Work hours/week $(n=548)$ & $32.14(20.0)$ & $1-92$ \\
Number of cigarette/day $(n=120)$ & $7.8(6.2)$ & $1-40$ \\
Drinking alcohol frequency/week $(n=209)$ & $3.0(1.7)$ & $1-7$ \\
Social support level $(n=1,775)$ & $15.0(3.1)$ & $2-20$ \\
Resiliency $(n=1,761)$ & $62.3(19.6)$ & $0-100$
\end{tabular}

Table 1.

Demographic, health history and social support of the participants
253

999

797

407

\section{3} . 


\begin{tabular}{|c|c|c|c|c|c|}
\hline Variables & Depression & Anxiety & Stress & Quality of life & tal h \\
\hline Age & 0.01 & 0.02 & -0.01 & $-0.12 * *$ & and quality $\mathrm{O}$ \\
\hline Marital status & $-0.09 * *$ & $-0.05^{*}$ & $-0.05^{*}$ & 0.03 & ariu quanty of \\
\hline Work hours/week & $-0.23 * *$ & $-0.23 * *$ & $-0.10^{*}$ & 0.06 & \\
\hline Family economic status & $-0.13 * *$ & $-0.06^{*}$ & -0.05 & $0.11 * *$ & \\
\hline ncy & $-0.07 *$ & $-0.16^{* *}$ & $-0.16^{* *}$ & $0.18^{* *}$ & \\
\hline Smoking status & 0.00 & -0.04 & $-0.07 * *$ & 0.02 & 913 \\
\hline Social support & $-0.27 * *$ & $-0.21 * *$ & $-0.23 * *$ & $0.28 * *$ & \\
\hline Resiliency & $-0.15^{* *}$ & $-0.14 * *$ & $-0.13^{* *}$ & $0.55^{* *}$ & \\
\hline \multicolumn{5}{|c|}{$\begin{array}{l}\text { Note(s): Spearman's Rho test was used with marital status, family economic status, exercise frequency, } \\
\text { smoking status and outcome variables (DASS and WHOQOL-OLD); Pearson's Product Moment test was used } \\
\text { with age, work hours/week, social support, resiliency and outcome variables (DASS and WHOQOL-OLD); } \\
*_{p}<0.05, * * p<0.01\end{array}$} & $\begin{array}{r}\text { Factors relat } \\
\text { depression, any } \\
\text { stress and qual } \\
\text { life among particir }\end{array}$ \\
\hline
\end{tabular}

\section{Predictors of depression}

Constant variables predicting depression, anxiety, stress, and quality of life were exercise, social support, and resiliency. After the statistical assumptions were checked, a hierarchical multiple regression was conducted to examine how well resiliency and social support can predict depression while controlling confounding variables. At step 1, when marital status, working hours per week, family economic status and exercise were entered, they significantly contributed to the regression model, $F(4,522)=11.66, p<0.001$ and accounted for $8 \%$ of the variance of depression (adjusted $R^{2}=0.08$ ). When social support and resiliency were added in step 2, they significantly improved the prediction, $R^{2}$ change $=.10, F(2,520)=32.05, p<0.001$. The entire group of variables significantly predicted depression, $F(6,520)=19.38, p<0.001$, adjusted $R^{2}=0.17$. However, only work hours per week, exercise, social support and resiliency significantly contributed to the model.

\section{Predictors of anxiety}

At step 1, when marital status, family economic status, working hours per week and exercise were entered, they significantly contributed to the regression model, $F(4,522)=13.74$, $p<0.001$ and accounted for $9 \%$ of the variance of anxiety (adjusted $R^{2}=0.09$ ). When social support and resiliency were added in step 2 , they significantly improved the prediction, $R^{2}$ change $=0.08, F(2,520)=25.82, p<0.001$. The entire group of variables significantly predicted anxiety, $F(6,520)=18.64, p<0.001$, adjusted $R^{2}=0.17$. However, only work hours per week, exercise, social support and resiliency significantly contributed to the model.

\section{Predictors of stress}

At step 1, when marital status, work hours per week, smoking status and exercise were entered, they significantly contributed to the model, $F(4,523)=7.45, p<0.001$ and accounted for $5 \%$ of the variance of stress (adjusted $R^{2}=0.05$ ). When social support and resiliency were added in step 2 , they significantly improved the prediction, $R^{2}$ change $=0.08, F(2$, $521)=22.63, p<0.001$. The entire group of variables significantly predicted stress, $F(6$, $521)=12.91, p<0.001$, adjusted $R^{2}=0.12$. However, only work hour per week, exercise, social support and resiliency significantly contributed to the model. 
JHR
36,5

\section{4}

\section{Predictors of quality of life}

At step 1, when age, family economic status and exercise were entered, they significantly contributed to the model, $F(3,1657)=34.85, p<0.001$ and accounted for $6 \%$ of the variance of stress (adjusted $R^{2}=0.06$ ). When social support and resiliency were added in step 2 , they significantly improved the prediction, $R^{2}$ change $=.29, F(2,1655)=370.51, p<0.001$. The entire group of variables significantly predicted quality of life, $F(5,1655)=178.44, p<0.001$, adjusted $R^{2}=0.35$ (Table 3 )

\section{Discussion}

Findings from this study indicated that resiliency, social support and exercise were important factors that positively contribute to both the mental health and quality of life of older adults in Thailand. Additionally, being active through part-time work positively influenced older adults' mental health while financial stability positively influenced their quality of life. The findings from this study were consistent with results from previous studies [9, 15-20].

In addition, previous study in Thailand recommended the development of intervention program to promote resiliency among older adults [10]. Another study in Thailand also found social support program to improve the quality of life among older adults [21]. Other programs for older adults include volunteer program to promote mental health [19] as well as active aging and health promotion to enhance mental wellbeing [22].

Based on the results from this study and recommendations from previous studies $[9,10$, 19-22], a comprehensive Wellness Program for Older Adults has been designed to improve the mental health and quality of life of older adults in Thailand (Figure 2). The proposed comprehensive Wellness Program for Older Adults has five components: Volunteer Program, Resiliency Building Program, Social Support Program, Exercise Program, and Financial Education Program.

Volunteer Program, including part-time work, has been indicated to help promote good mental health [19]. Volunteer and part-time work activities help older adults stay active and engaged as well as connect with other people and reduce social isolation. In addition, for older adults with some financial challenges, working part-time could also provide a source of income in addition to helping with their mental health. Local community can design culturally appropriate volunteer program for older adults that meets the either local or national needs by using local wisdom and knowledge. For example, OTOP

\begin{tabular}{lrrrrr}
\hline Variables & $\mathrm{B}$ & $S E B$ & $\beta$ & $R^{2}$ & $\Delta R^{2}$ \\
\hline Step 1 & & & & 0.06 & 0.06 \\
Age & -0.15 & 0.04 & $-0.10^{* * * *}$ & & \\
Family economic status & 2.65 & 0.49 & $0.13^{* * *}$ & & \\
Exercise frequency & 1.81 & 0.25 & $0.18^{* * *}$ & & \\
Constant & 70.97 & 3.00 & & 0.35 & 0.29 \\
Step 2 & & & & & \\
Age & -0.11 & 0.03 & $-0.07 * * *$ & & \\
Family economic status & 1.04 & 0.42 & $0.05^{*}$ & \\
Exercise frequency & 0.84 & 0.21 & $0.08^{* * *}$ & & \\
Social support & 0.52 & 0.07 & $0.15^{* * *}$ & \\
Resiliency & 0.28 & 0.01 & $0.51^{* * * *}$ & & \\
Constant & 49.34 & 2.67 & & & \\
Note(s): $* p<0.05, * * p<0.01, * * * p<0.001$ & & & &
\end{tabular}

Note(s): $* p<0.05, * * p<0.01, * * * p<0.001$
Table 3.

Hierarchical multiple regression analysis summary for social support and resiliency, controlling demographic and health history, predicting quality of life 


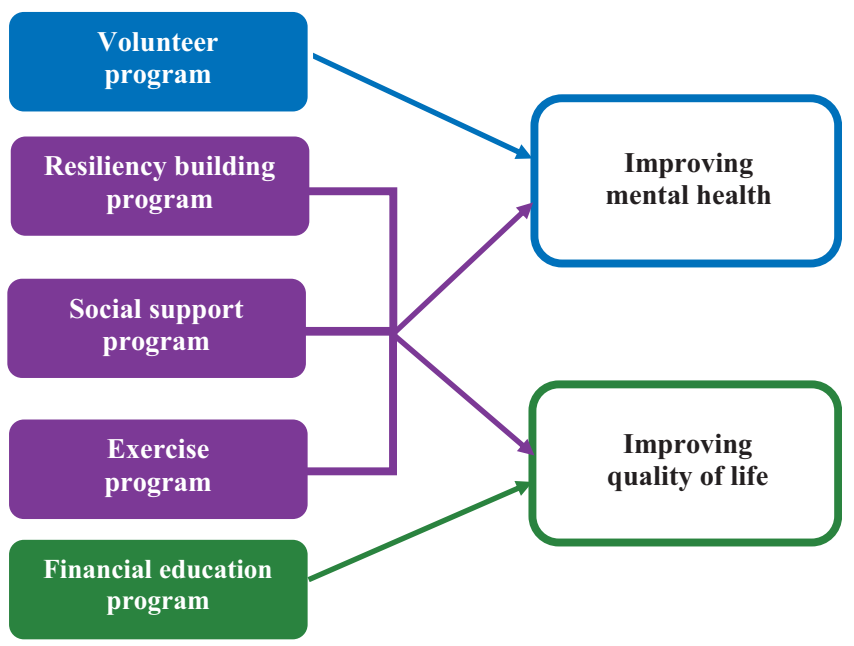

Program (One Tambon One Product) has been created in Thailand to stimulate economic growth in rural communities and support unique locally made products throughout the country. Older adults in various parts of Thailand can be involved with existing OTOP products or work together with the community to create new products based on local resources.

Resiliency building program can be designed to help older adults focus on gratitude and positive emotions, talk about negative experiences, increase self-efficacy, as well as enhance support resources, improve personal competence and increase tolerance of negative affect [9]. Some resilience building activities that will work well with local Thai older adult communities include overlapping activities of other Wellness Program components such as volunteering, joining support groups, exercising with others as well as

\section{Building resilience}

(1) University of California, Berkeley - Greater Good Science Center: https:/greatergood.berkeley.edu/article/ item/five_science_backed_strategies_to_build_resilience

(2) American Psychological Association: https://www.apa.org/topics/resilience

(3) University of Arizona - Center on Aging: https://nursingandhealth.asu.edu/sites/default/files/resiliencein-aging.pdf

Exercise program

(1) Harvard Medical School: https://www.health.harvard.edu/staying-healthy/exercise_after_age_70

(2) Centers for Disease Control and Prevention (CDC): https://www.cdc.gov/physicalactivity/basics/older adults/index.htm

(3) National Council on Aging (NCOA): https:/www.ncoa.org/center-for-healthy-aging/basics-of-evidencebased-programs/physical-activity-programs-for-older-adults/

Financial education

(1) National Council on Aging (NCOA): https:/www.ncoa.org/economic-security/money-management/ budgeting/savvy-saving-seniors-financial-education/

(2) Age UK: https://www.ageuk.org.uk/information-advice/money-legal/

(3) Federal Deposit Insurance Corporation (FDIC): https://www.fdic.gov/consumers/consumer/moneysmart/ olderadult.html

Table 4. Online resources 
JHR

36,5

916

mindfulness meditation, journaling, healthy eating and discovering life's purpose. Additional sample programs for building resilience that can be adapted to utilize with the local community are listed in Table 4.

Social support program has the main goal of helping older adults feel supported by family and friends which have been found to improve their well-being [20]. Various activities that can help achieve this goal include joining a support group, taking classes at the elderly school, participating in events at the community center, and spending time with family members during the holidays.

Exercise program can be designed to include low-impact activities that improve strength, flexibility, balance and cardiovascular condition. Regular exercise in a group context can also build a sense of community while preventing some health problems that come with the aging process. An active aging program will not only improve physical health, but also mental health and quality of life for older adults. See Table 4 for sample online resources for exercise programs that can be adapted to use with the local community.

Financial education program is the last component of the Wellness Program that includes two parts: establishing financial stability and protecting against financial fraud. Learning how to budget is an important key to establishing financial stability. Older adults need to learn to keep track of their income and expenses. Additionally, there has been increasing financial crime that target the vulnerable older adult population. Globally, millions of older adults become victims of financial scams each year. The second part of the financial education includes fraud prevention strategies through awareness of scams that have been used among older adults. Sample online financial education resources are listed in Table 4. These resources could be adapted to use in the local context for various countries.

Together, these five Wellness Program components can contribute to the improvement of the mental health and quality of life of older adults. Limitations for this study include the use of quantitative cross-sectional survey design. Future research could utilize mixedmethod approach to include more in-depth interviews of older adults. Additional research studies are also needed to evaluate the effectiveness of the proposed Wellness Program for Older Adults.

\section{Conclusions}

With a rapidly increasing older adult population, more efforts are needed to understand their mental health, quality of life and associated factors. Results from this study indicate resiliency, social supportand exercise to be significant predictors of mental health and quality of life. It is important for older adults, their family members, community leaders and public health professionals to take a proactive stance to help improve the mental health and quality of life of the older adult population. Volunteer Program, Resiliency Building Program, Social Support Program, Exercise Program and Financial Education Program are examples of programs that can improve the mental health and quality of life of older adults. All the components of the Wellness Program can be implemented at the local community without requiring a lot of financial resources and will contribute to the long-term wellness and improved quality of life among older adults.

Conflicts of Interest: None

\section{References}

1. United Nations, Department of Economic and Social Affairs, Population Division. World population prospects 2019: highlights. [cited 2021 February 9]. Available at: https://population.un. org/wpp/Publications/Files/WPP2019_Highlights.pdf. 
2. United Nations, Department of Economic and Social Affairs, Population Division. World population ageing 2019: highlights. [cited 2021 February 9]. Available at: https://www.un.org/en/development/ desa/population/publications/pdf/ageing/WorldPopulationAgeing2019-Highlights.pdf.

3. Choowattanapakorn T, Aléx L, Lundman B, Norberg A, Nygren B. Resilience among women and men aged 60 years and over in Sweden and in Thailand. Nurs Health Sci. 2010; 12(3): 329-35. doi: 10.1111/j.1442-2018.2010.00534.x.

4. Suttajit S, Punpuing S, Jirapramukpitak T, Tangchonlatip K, Darawuttimaprakorn N, Stewart R, et al. Impairment, disability, social support and depression among older parents in rural Thailand. Psychol Med. 2010; 40(10): 1711-21. doi: 10.1017/s003329170999208x.

5. Boonsawad P, Petchlorlian A, Tongboonchoo C, Rattanavicha W, Duangduen Y. Resilience in older adults at wellness center. J Royal Thai Army Nurs. 2020; 21(3): 481-90.

6. Charoensakulchai S, Usawachoke S, Kongbangpor W, Thanavirun P, Mitsiriswat A, Pinijnai O, et al. Prevalence and associated factors influencing depression in older adults living in rural Thailand: a cross-sectional study. Geriatr Gerontol Int. 2019; 19(12): 1248-53. doi: 10.1111/ ggi.13804.

7. Yuenyongchaiwat K, Pongpanit K, Hanmanop S. Physical activity and depression in older adults with and without cognitive impairment. Dement Neuropsychol. 2018; 12(1): 12-8. doi: 10.1590/ 1980-57642018dn12-010002.

8. Connor KM, Davidson JR. Development of a new resilience scale: the Connor-Davidson resilience scale (CD-RISC). Depress. Anxiety. 2003; 18(2): 76-82. doi: 10.1002/da.10113.

9. MacLeod S, Musich S, Hawkins K, Alsgaard K, Wicker ER. The impact of resilience among older adults. Geriatr Nurs. 2016; 37(4): 266-72. doi: 10.1016/j.gerinurse.2016.02.014.

10. Toonsiri C, Hengudomsub P, Chaimongkol N, Photihung P. Factors influencing resilience among community-dwelling older adults with chronic illness: a causal model testing. J Fac Nurs Burapha Univ. 2019; 27(1): 78-88.

11. Wu M, Yang Y, Zhang D, Zhao X, Sun Y, Xie H, et al. Association between social support and health-related quality of life among Chinese rural elders in nursing homes: the mediating role of resilience. Qual Life Res. 2018; 27(3): 783-92. doi: 10.1007/s11136-017-1730-2.

12. McGillivray K, Ho R. Validation of the Connor Davidson resilience scale (CD-RISC) as applied within the Thai context. Scholar: Human Sciences. 2016; 8(2): 178-87.

13. Lovibond SH, Lovibond PF. Manual for the depression anxiety stress scales. 2nd ed. Sydney: Psychology Foundation; 1995.

14. Power M, Quinn K, Schmidt S, WHOQOL-OLD Group. Development of the WHOQOL-old module. Qual Life Res. 2005; 14(10): 2197-214. doi: 10.1007/s11136-005-7380-9.

15. Azizan A, Justine M. Effects of a behavioral and exercise program on depression and quality of life in community-dwelling older adults: a controlled, quasi-experimental study. J Gerontol Nurs. 2016; 42(2): 45-54. doi: 10.3928/00989134-20151124-01.

16. Reyes MF, Satorres E, Meléndez JC. Resilience and socioeconomic status as predictors of life satisfaction and psychological well-being in Colombian older adults. J Appl Gerontol. 2020; 39(3): 269-76. doi: 10.1177/0733464819867554.

17. Tangchonlatip K, Chamratrithirong A, Lucktong A. The potential for civic engagement of older persons in the ageing society of Thailand. J Health Res. 2019; 33(5): 386-97. doi: 10.1108/JHR-082018-0083.

18. Wang Y, Zhang J, Wang B, Fu H. Social support from adult children, parent-child relationship, emotion regulation strategy, and depressive symptoms among Chinese older adults. Res. Aging. 2020; 42(9-10): 281-90. doi: 10.1177/0164027520930973.

19. Greenfield EA, Marks NF. Formal volunteering as a protective factor for older adults' psychological well-being. J Gerontol B Psychol Sci Soc Sci. 2004; 59(5): S258-64. doi: 10.1093/ geronb/59.5.s258.

\section{Older adult mental health and quality of life}

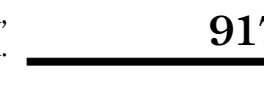


JHR

36,5

918
20. Chen Y, Feeley TH. Social support, social strain, loneliness, and well-being among older adults: an analysis of the health and retirement study. J Soc Pers Relat. 2014; 31(2): 141-61. doi: 10.1177/ 0265407513488728.

21. Sampoon K, Posri N, Kittichotpanich B. Application of social dance exercise and social support program to improve quality of life for Thai older adults. J Health Res. 2019; 33(3): 260-6. doi: 10. 1108/JHR-08-2018-0071.

22. Loke YJ, Lim ES, Senadjki A. Health promotion and active aging among seniors in Malaysia. J Health Research. 2020; Advanced online publication. doi: 10.1108/JHR-07-2019-0148.

\section{Corresponding author}

Paul Ratanasiripong can be contacted at: paul.ratanasiripong@csulb.edu

For instructions on how to order reprints of this article, please visit our website: 